\title{
Predicting copper-, iron-, and zinc-binding proteins in pathogenic species of the Paracoccidioides genus
}

\author{
Gabriel B. Tristão ${ }^{1}$, Leandro do Prado Assunção ${ }^{1}$, Luiz Paulo A. dos Santos ${ }^{1}$, Clayton L. Borges ${ }^{1}$, \\ Mirelle Garcia Silva-Bailão ${ }^{1}$, Célia M. de Almeida Soares ${ }^{1}$, Gabriele Cavallaro ${ }^{2}$ and \\ Alexandre M. Bailão ${ }^{1 *}$
}

${ }^{1}$ Biochemistry and Molecular Biology, Laboratório de Biologia Molecular, Universidade Federal de Goiás, Goiânia, Brazil

${ }^{2}$ Magnetic Resonance Center, University of Florence, Sesto Fiorentino, Italy

\section{Edited by:}

Joshua D. Nosanchuk, Albert

Einstein College of Medicine of Yeshiva University, USA

\section{Reviewed by:}

Marcio Rodrigues, Oswaldo Cruz Foundation, Brazil

Charley Christian Staats,

Universidade Federal do Rio Grande do Sul, Brazil

\section{*Correspondence:}

Alexandre M. Bailão, Laboratório de Biologia Molecular, Departamento de Bioquímica, Instituto de Ciências Biológicas II, Universidade Federal de Goiás, Goiânia-GO, Estrada do campus, Campus Samambaia, ICB2, room 206, Goiania, Brazil e-mail: alexandre.bailao@gmail.com
Approximately one-third of all proteins have been estimated to contain at least one metal cofactor, and these proteins are referred to as metalloproteins. These represent one of the most diverse classes of proteins, containing metal ions that bind to specific sites to perform catalytic, regulatory and structural functions. Bioinformatic tools have been developed to predict metalloproteins encoded by an organism based only on its genome sequence. Its function and the type of metal binder can also be predicted via a bioinformatics approach. Paracoccidioides complex includes termodimorphic pathogenic fungi that are found as saprobic mycelia in the environment and as yeast, the parasitic form, in host tissues. They are the etiologic agents of Paracoccidioidomycosis, a prevalent systemic mycosis in Latin America. Many metalloproteins are important for the virulence of several pathogenic microorganisms. Accordingly, the present work aimed to predict the copper, iron and zinc proteins encoded by the genomes of three phylogenetic species of Paracoccidioides (Pb01, Pb03, and Pb18). The metalloproteins were identified using bioinformatics approaches based on structure, annotation and domains. $\mathrm{Cu}-, \mathrm{Fe}-$, and Zn-binding proteins represent $7 \%$ of the total proteins encoded by Paracoccidioides spp. genomes. Zinc proteins were the most abundant metalloproteins, representing $5.7 \%$ of the fungus proteome, whereas copper and iron proteins represent 0.3 and $1.2 \%$, respectively. Functional classification revealed that metalloproteins are related to many cellular processes. Furthermore, it was observed that many of these metalloproteins serve as virulence factors in the biology of the fungus. Thus, it is concluded that the $\mathrm{Cu}, \mathrm{Fe}$, and $\mathrm{Zn}$ metalloproteomes of the Paracoccidioides spp. are of the utmost importance for the biology and virulence of these particular human pathogens.

Keywords: metalloproteome, bioinformatics, Paracoccidioidomycosis, metal homeostasis, virulence

\section{INTRODUCTION}

Metal ions such as copper, iron, and zinc and others play an essential role in living organisms primarily by virtue of their association with proteins, which are referred to as metalloproteins (Frausto Da Silva and Williams, 1991; Bertini et al., 2007; Festa and Thiele, 2011). Approximately one-third of all proteins studied are associated with a metal ion (Shi and Chance, 2008) whose presence is most commonly needed for the catalytic mechanism of enzymes and/or the stabilization of the tertiary or quaternary structure of proteins (Andreini et al., 2006a).

Many metals play important roles in organisms as a free ion or coupled to proteins. However, the function of $\mathrm{Cu}, \mathrm{Fe}$, and $\mathrm{Zn}$ is primarily related to metalloprotein dependence on those elements. Copper essentiality retains both its activity in structural stabilization and its redox ability, which is used by metalloenzymes that catalyze electron transfer reactions (Festa and Thiele, 2012). In this respect, this metal functions in a broad range of metabolic activities including, for example, energy production, iron acquisition, melanin production and antioxidant defense
(Kim et al., 2008). Iron is also a redox-active element and is essential as a cofactor in the form of heme and iron-sulfur clusters in a variety of cellular processes such as respiration, amino acid metabolism, biosynthesis of sterols and DNA, peroxide detoxification, and DNA replication (Nevitt, 2011; Schrettl and Haas, 2011; Netz et al., 2012). Zinc constitutes the catalytic and/or structural core of many proteins involved, among other functions, in transcriptional control, reactive oxygen species (ROS) detoxification, carbohydrate oxidation and alcoholic fermentation (Murakami and Hirano, 2008; Wilson et al., 2012).

Although metals are fundamental for the correct functioning of cells, their excess is toxic. Thus, metal availability is tightly controlled (Valko et al., 2005; Bleackley and Macgillivray, 2011). During infection there is a battle for micronutrients where a host can either decrease metal availability to the invader or increase the metal concentration to toxic levels, and pathogens must keep metal homeostasis in host tissues to promote a successful infection (Ammendola et al., 2007; Samanovic et al., 2012; Wilson et al., 2012; Cassat and Skaar, 2013). A prerequisite to 
understanding the homeostatic mechanisms that maintain constant levels of the essential metals and removing the unwanted metals in an organism is the knowledge, as complete as possible, of the metalloproteins encoded by that organism. With the advent of genome sequencing, the entire proteome of several species has become available. For the majority of these data, however, there is no functional information available, as a thorough functional characterization of whole proteomes is not yet routinely possible. Thus, a systematic approach to search metalloproteins in protein sequence databases has been developed (Andreini et al., 2004) and used in a systematic description of copper, iron and zinc proteins through the three domains of life (Andreini et al., 2006b, 2007, 2008).

Paracoccidioidomycosis is a systemic mycosis restricted to Latin American countries. This disease is caused by the fungi of the species complex Paracoccidioides spp. The complex is composed of two species: Paracoccidioides lutzii and Paracoccidioides brasiliensis; the latter has four phylogenetic species, S1, PS2, PS3, and PS4, with a different geographic distribution (Matute et al., 2006a,b; Carrero et al., 2008; Teixeira et al., 2009, 2013; Bocca et al., 2013). Paracoccidioides spp. are thermodimorphic fungi that present as mycelium in the environment at temperatures of $18-25^{\circ} \mathrm{C}$ and as yeast in mammalian hosts at $36^{\circ} \mathrm{C}$. Metal homeostasis has been well described as a determinant factor in fungal pathogenesis (Bailao et al., 2006; Schrettl and Haas, 2011; Festa and Thiele, 2012; Schneider Rde et al., 2012; Wilson et al., 2012), and Paracoccidioides spp. presents several metal homeostasis genes that encode for molecules that have been described as important virulence factors in fungi (Silva et al., 2011). In the present work, we used the abovementioned bioinformatics approach to predict the $\mathrm{Cu}-, \mathrm{Fe}-$, and $\mathrm{Zn}$-binding proteins encoded by the genomes of the genus Paracoccidioides, with the aim of advancing our comprehension of the fungal metal homeostasis and virulence.

\section{MATERIALS AND METHODS \\ IDENTIFICATION OF Cu-, Fe-, AND Zn-BINDING PROTEINS IN THE PARACOCCIDIOIDES SPP. GENOME}

Metalloproteins were identified by using the RDGB tool (Andreini et al., 2011) with default options. In the RDGB strategy, the protein domains defined in the Pfam library are used to identify putative homologs in any desired genome or list of genomes. Copper-, iron-, and zinc-binding Pfam domains were initially identified in the sequence of copper-, iron-, and zincbinding proteins of known 3D structures, which are available from the Protein Data Bank (PDB). When a particular metal is present within the $3 \mathrm{D}$ structure of the protein, this information can be readily extracted from the PDB database along with the pattern of amino acids that are involved in the interaction of the protein with the metal.

The latter is referred to as the ligand binding pattern (LBP) and is defined by the identity and spacing of the amino acids, e.g., $\mathrm{CX}(4) \mathrm{CX}(2) \mathrm{H}$, where $\mathrm{X}$ is any amino acid. This pattern is usefully applied as a filter to reduce the number of false positives (i.e., of the proteins predicted to bind the metal, which in reality are unable to bind it) by rejecting the proteins that lack the LBP. The LBP filter is applied by imposing that the predicted protein contains all of the ligands of the LBP with a spacing in sequence that it is maintained within $\pm 20 \%$ (or \pm 1 amino acid for short spacing). The lists of copper-, iron-, and zincbinding Pfam domains were manually refined before being used in the RDGB protocol by (I) removing the domains that did not bind the metal(s) physiologically, and (II) adding domains that were known to bind the metal(s) physiologically, although no 3D structure was available. The latter refinement is based on the annotation present in the Pfam database, which is sufficiently detailed to allow users to evaluate the actual relevance of a domain to the biochemistry under investigation (in this case, the metalbinding properties). In further detail, for each domain in the list, the annotation is examined to confirm that the domain physiologically binds that metal. If this is not the case (e.g., due to adventitious binding during crystallization or purification procedures), then the domain is rejected. When the Pfam annotation alone is not sufficient to establish whether a metal is physiologically bound, the relevant literature is analyzed. Additionally, the Pfam is queried for those domains whose annotation contains the name and/or the symbol of the metal. This typically provides additional domains that lack structural characterization but have been identified as binding a specific metal. Again, the relevant literature is also investigated.

As reported in the original RDGB paper (Andreini et al., 2011), the RDGB performance parameters are evaluated as follows: sensitivity $[\mathrm{TP} /(\mathrm{TP}+\mathrm{FN})]=97.7 \%$; specificity $[\mathrm{TN} /(\mathrm{TN}+\mathrm{FP})]=$ $78.8 \%$; precision $[\mathrm{TP} /(\mathrm{TP}+\mathrm{FP})]=85.9 \%$; and accuracy $[(\mathrm{TP}+$ $\mathrm{TN}) /(\mathrm{TP}+\mathrm{TN}+\mathrm{FP}+\mathrm{FN})]=89.6 \%$.

FUNCTIONAL CLASSIFICATION, LOCALIZATION AND COMPARISONS OF Cu-, Fe-, AND Zn-BINDING PROTEINS FROM PARACOCCIDIOIDES SPP.

The predicted metalloproteins of $P$. lutzii $P b 01$ and $P$. brasiliensis $P b 18$ and $P b 03$ were functionally classified with the FunCat2 scheme accessed on the Pedant database (http://pedant.gsf.de/) (Walter et al., 2009). The WolfPsort system was used to predict the putative cell localization of the proteins. The homology comparison among the metalloproteomes of the three species was performed using the BLAST tool. The metalloproteins of one phylogenetic species were compared to the corresponding metalloproteome of the two other species to find the orthologs. The structural analysis was performed to ascertain that the bound metal was completed with the I-Tasser algorithm (http://zhanglab.ccmb.med.umich.edu/I-TASSER/). BLAST and I-Tasser were used in the analysis of the species-exclusive metalloproteins. When the BLAST comparison of the metalloprotein databank results indicated a specific protein, the sequence was compared against the whole proteome and the structure of the protein was predicted. To study the potential functional associations among the copper proteins having representatives in all Paracoccidioides spp., a COG identification number was associated with these proteins. The list of COG identification numbers was then used to query the STRING database (Von Mering et al., 2003).

\section{CULTURE CONDITIONS AND EXPRESSION ANALYSIS BY qRT-PCR}

Yeast cells of $P$. lutzii were maintained in a solid Fava Neto's medium at $37^{\circ} \mathrm{C}$. The yeasts were grown in a liquid medium 
for $72 \mathrm{~h}$ at $37^{\circ} \mathrm{C}$. The cells were harvested by centrifugation and washed twice with a phosphate saline buffer and then transferred to the chemically defined medium MMcM (Restrepo and Jimenez, 1980). The iron limiting condition was generated without the addition of iron sources and the supplementation of the iron chelator BPS (bathophenanthroline-disulfonic acid) at $50 \mu \mathrm{M}$. The iron excess condition was induced by adding ammonium ferrous sulfate at 50 and $100 \mu \mathrm{M}$. Control cells were incubated in a MMcM medium with $3.5 \mu \mathrm{M}$ of iron. The RNA extraction and quantitative RT-PCR was performed as previously described (Silva-Bailao et al., 2014). The oligonucleotides used in the PCR amplification were: Ca-transporter FW 5'- GTCGAACGAGGCAATGAGAGAG-3'; Ca-transporter RV $5^{\prime}$ - TTGTAAAATCTTGCGCTTCGGG-3'; $\alpha$-tubulin FW $5^{\prime}$-ACAGTGCTTGGGAACTATACC- $3^{\prime}$; and $\alpha$-tubulin RV $5^{\prime}$ GGGACATATTTGCCACTGCC-3'.

\section{RESULTS}

\section{IDENTIFICATION OF COPPER-, IRON-, AND ZINC-BINDING PROTEINS IN PARACOCCIDIOIDES SPP. GENOMES}

The genomes of three phylogenetic species of the Paracoccidioides spp. complex were analyzed for $\mathrm{Cu}, \mathrm{Fe}$, and $\mathrm{Zn}$ proteins using two complementary approaches: all of the metal binding patterns (MBP) were retrieved from the PDB and used along with sequence analysis to scan the proteins; additionally, a library of metal-binding protein domains based on multiple sequence alignments of known metalloproteins was used (taken from Pfam) to browse the predicted proteome (Andreini et al., 2006a). In total, 25,753 proteins from the three completely predicted proteomes were subjected to analysis and 1952 metalloproteins were detected. The results also show that those proteins represent, on average, $7.6 \%$ of the predicted proteome of these fungi (Table 1).

The most abundant metalloproteins were zinc-binding followed by iron-binding and copper-binding (Supplementary Tables 1-3). A higher frequency of Zn-binding proteins was expected because zinc is one of the most abundant metal ions in living organisms, playing two major roles: catalytic and structural. Some of the identified metalloproteins presented ambiguity between their annotation and the identified metal domain (e.g., proteins PAAG_06410, PADG_01717, PAAG_03944, and PAAG_02157). These molecules were subjected to structural analysis and $70 \%$ were found to have the same metal (Supplementary Table 4), whereas 30\% presented other putative metals, such as $\mathrm{Mn}$ and $\mathrm{Ca}$. Some proteins presented two possible ligand metals. The most frequent combinations were $\mathrm{Fe} / \mathrm{Zn}$ followed by $\mathrm{Cu} / \mathrm{Zn}$ and $\mathrm{Cu} / \mathrm{Fe}$ (Table 2 ). To investigate the results of the metalloproteins with two bound metals, the

Table 1 | Number of metalloproteins identified in the Paracoccidioides spp. genome.

\begin{tabular}{lcccc}
\hline $\begin{array}{l}\text { Paracoccidioides } \\
\text { sp. }\end{array}$ & $\begin{array}{c}\text { Predicted } \\
\text { proteome }\end{array}$ & $\begin{array}{c}\text { Cu proteins } \\
(\mathbf{\%})\end{array}$ & $\begin{array}{c}\text { Fe proteins } \\
\text { (\%) }\end{array}$ & $\begin{array}{c}\text { Zn proteins } \\
\text { (\%) }\end{array}$ \\
\hline P. lutzii (Pb01) & 9136 & $26(0.28)$ & $115(1.25)$ & $522(5.71)$ \\
Pb18 & 8741 & $25(0.28)$ & $115(1.31)$ & $511(5.84)$ \\
Pb03 & 7876 & $26(0.33)$ & $111(1.40)$ & $501(6.38)$
\end{tabular}

protein structure was predicted using the I-Tasser software. This approach revealed that 11.9\% (Pb01), 17.5\% (Pb03) and 13.5\% (Pb18) of the proteins present motifs for two metals and most of them corroborate with the MBP-based prediction. The remaining metalloproteins presented only one ligand metal, and 62.1 to $81.8 \%$ of the structures were in consonance with the results based on the MBP and Pfam domains (Supplementary Table 4). The list of the metalloproteins identified in this work is available at http://www.broadinstitute.org/annotation/genome/paracoccidioides_brasiliensis/MultiHome.html.

\section{COPPER PROTEINS}

The bioinformatics analysis showed that $26 \mathrm{Cu}$-binding proteins were found in the P. lutzii and Pb03 genomes, whereas 25 were found in the $\mathrm{Pb} 18$ genome. Functional classification of the $\mathrm{Cu}$ proteins revealed that ion transport and melanin synthesis are the most enriched functional categories because 6 copper transporters and 3 laccases were found (Figure 1). Not surprisingly, the high-affinity copper transporter whose expression is induced in infection-like conditions (Bailao et al., 2006; Costa et al., 2007) belongs to the predicted copper proteome. Although only two proteins related to stress response were found, it is important to highlight that the two superoxide dismutases are copper dependent. Additionally, three amino oxidases contain a $\mathrm{Cu}$ domain, suggesting the relevance of this metal for their catalysis. In silico analysis also showed that 5 hypothetical proteins (Supplementary Table 1) present a Cu-binding domain. The copper proteins present in the three PS were analyzed in search of potential functional associations. To accomplish this, a COG identification number was associated with each ortholog group. According to the STRING database, 11 of 19 copper proteins are interconnected by high functional associations ( score $=0.99$ ) as shown in Figure 2. The interaction network represents a combination of different pieces of evidence that there are relationships of a functional nature among the proteins. In fact, the linkages between the pairs reveals that $\mathrm{Cu}$-chaperone and $\mathrm{Cu}$-transporting ATPase are core proteins that are functionally essential to metal homeostasis because the former binds to and distributes copper in the cell and the latter transports and keeps copper level in the Golgi apparatus for copper proteins such as laccases. Additionally, cu-superoxide dismutase and laccase interact with many cu-binding molecules, suggesting their participation in Cu homeostasis (Figure 2).

The cell localization prediction analysis corroborates the functional analysis and annotation of $\mathrm{Cu}$-proteins (Supplementary Tables 1-3). The results indicate a high frequency of such proteins at the membranes as a result of the high numbers of copper transporters. The number of secreted proteins was also high. Among the molecules predicted to reach the extracellular environment are laccases, SOD, amine oxidase, polyphenoloxidase, and

Table 2 | Number of proteins with two metal-binding domains.

\begin{tabular}{lccc}
\hline Paracoccidioides spp. & $\mathbf{C u} \times \mathbf{F e}$ & $\mathbf{C u} \times \mathbf{Z n}$ & $\mathbf{F e} \times \mathbf{Z n}$ \\
\hline P. lutzii & 2 & 6 & 34 \\
Pb18 & 2 & 5 & 30 \\
Pb03 & 2 & 7 & 31
\end{tabular}




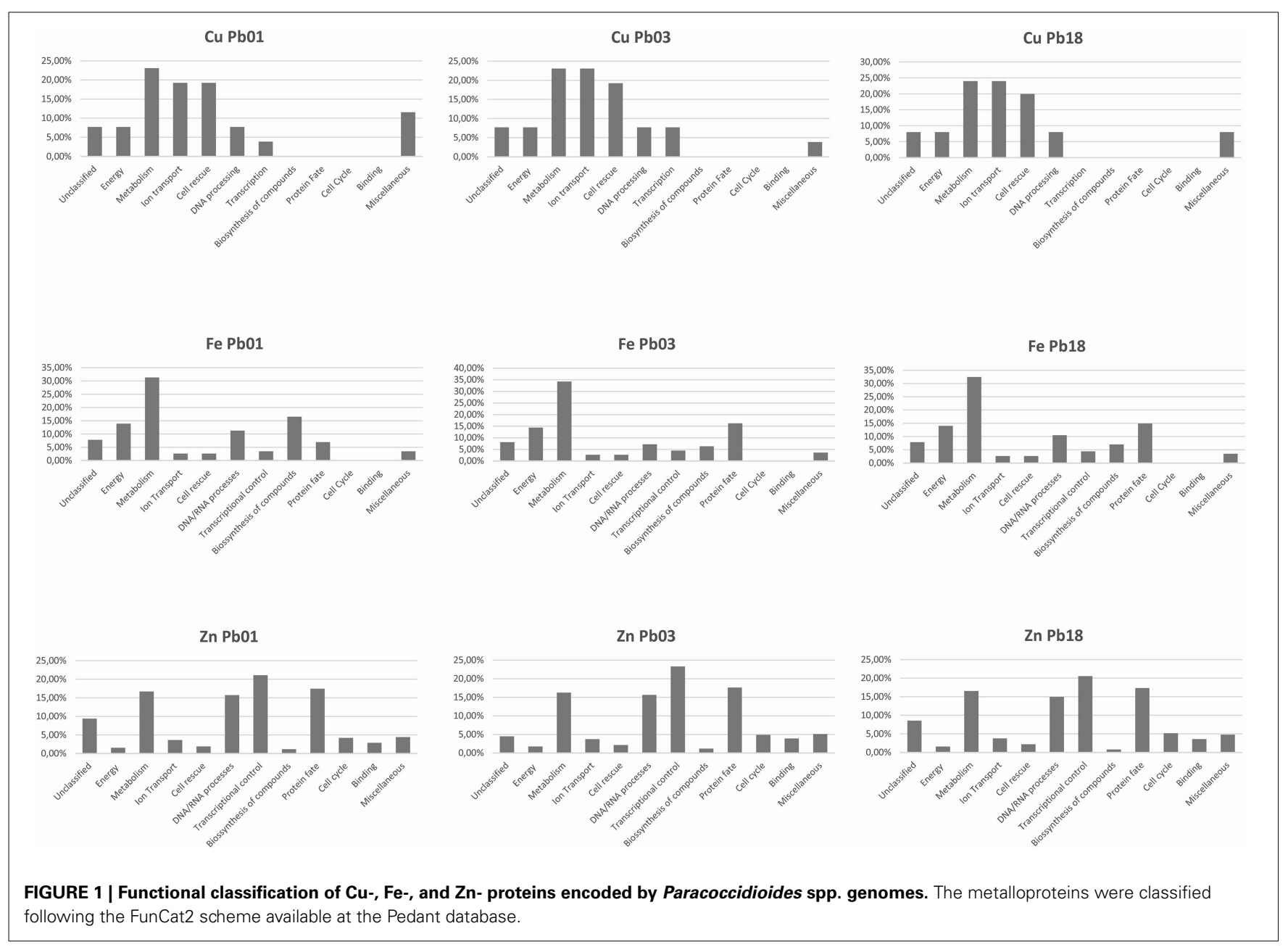

tyrosinase. As expected, the majority of the $\mathrm{Cu}$-containing proteins were localized in cytoplasm for general metabolism-related enzymes. Because of its function in the electron-transfer chain, some copper proteins were localized at the mitochondrion.

\section{IRON PROTEINS}

The three genomes encode for 115, 111, and 115 proteins in $\mathrm{Pb} 01$, $\mathrm{Pb} 03$, and P18, respectively. The general cell metabolism functions were the most enriched category; the primary reason is explained by the presence of many dehydrogenases that catalyze oxide-reduction reactions that use iron to promote electrontransfer processes. Of special note, the metabolism of amino acids and vitamins were highly represented inside this class. Additionally, many protein phosphatases were associated to iron, as expected. Iron proteins related to TCA and electron transfer chains that use iron-sulfur clusters that are essential in aerobic energy production were also found (Figure 1). Accordingly, ironsulfur cluster assembling proteins compose the iron-proteome of the genus Paracoccidioides. Intriguingly, no iron transporter was found using in silico analysis. Actually, a calcium transporter (PAAG_07762; PABG_00362; PADG_02775) was found and, consequently, the 3D modeling was built to solve this ambiguity. The analysis showed that this transporter presents iron as a ligand (Figure 3) suggesting that this transporter could act in iron homeostasis in this fungus because no specific iron transporters were found in the genomes available (Silva et al., 2011). To confirm that, expression levels of this transporter were analyzed in conditions with low iron availability and with iron excess. The transcript levels encoding the transporter were decreased in iron deprivation and increased in iron excess suggesting this protein is probably related to iron detoxification more than iron uptake (Figure 4). A urease containing iron as a ligand was also found. However, most of the urease structures available in the PDB are Ni-dependent proteins and only two ureases from bacteria are iron dependent (Carter et al., 2011). Paracoccidioides spp. ureases present a higher identity with iron-binding enzymes (57\%; PDB ID 3QGA) than with Ni-dependent enzymes (41\%; PDB ID 1E9Y; data not shown). Among the iron-binding proteins, three superoxide dismutases were detected.

Most of the iron proteins were predicted to localize in the mitochondrion and cytoplasm. This observation corroborates with the cell processes performed by such molecules. The energy production and electron transfer reactions classically occur in the mitochondrion of eukaryotes. Additionally, proteins related to general metabolic events (amino acid metabolism, carbohydrate metabolism) are predicted to localize in cytosol. Moreover, the 


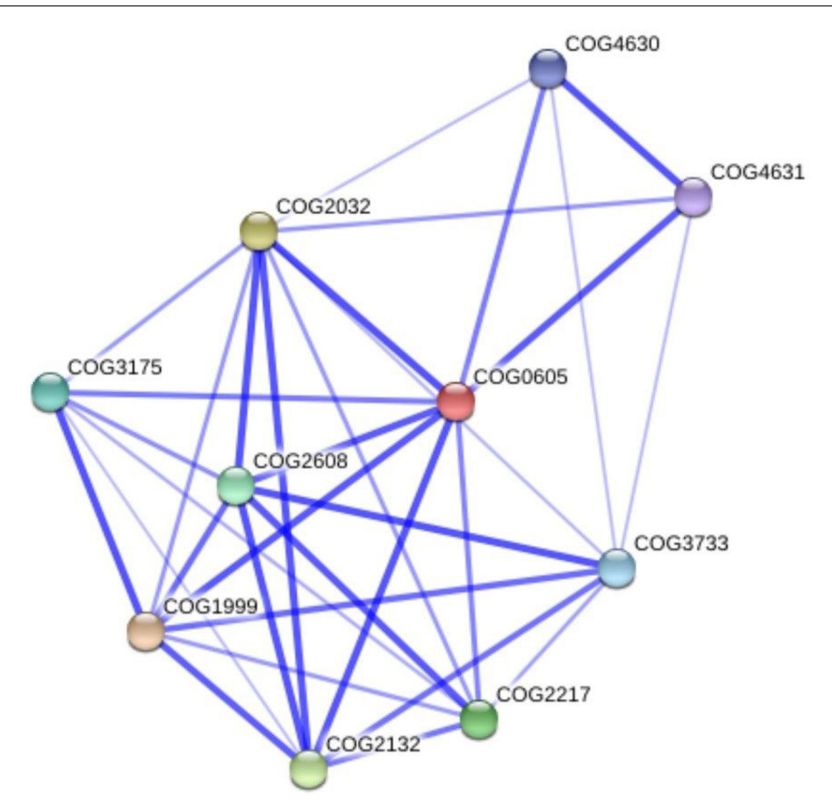

FIGURE 2 | Functional interaction graph of copper proteins from P. lutzii predicted proteome. The graph was constructed in the STRING tools using standard parameters. Cu-proteins found in the present study: COG3733 copper amine oxidase; COG2608 copper-transporting P-type ATPase; COG2217 copper-transporting ATPase; COG1999 mitochondrial metallochaperone Sco1; COG2132 laccase IV; COG2032 superoxide dismutase; COG0605 cytosolic Cu/Zn superoxide dismutase; COG4631 xanthine dehydrogenase; COG4630 xanthine dehydrogenase; COG3175 cytochrome c oxidase assembly protein ctaG.

plasma membrane and nucleus are cell organelles that contain iron proteins.

\section{ZINC PROTEINS}

Prediction of the Paracoccidioides spp. Zn proteomes revealed that zinc proteins are the most abundant metalloproteins encoded by their genome in comparison to $\mathrm{Fe}$ and $\mathrm{Cu}$ proteins. More than 500 zinc-binding proteins were found to be encoded for each genome (Supplementary Table 1). The most enriched functional categories in the $\mathrm{Zn}$ proteome were those related to transcription, cell cycle, and DNA processing, as well as protein fate and modification. Many zinc finger domain containing transcription factors were identified, which contributed to the functional enrichment. Regarding protein fate and modification, many peptidases and proteases were found to be zinc dependent. Additionally, proteins related to phosphorylation and ubiquitination were abundant in this category (Figure 1). Unlike the $\mathrm{Cu}$ - and Fe-proteomic data, several metal transporters compose the predicted zinc proteome of the complex Paracoccidioides spp. Accordingly, zinc-, metal specific- (other than zinc), heavy metal-, and cation-transporters were found to be zinc binding molecules. A considerable portion of the $\mathrm{Zn}$ proteome did not present describe function, reinforcing the fact that the role of metals in several cellular events is beyond the current knowledge. Many $\mathrm{Zn}$ proteins are related to nucleic acid related processes and metabolism. Consequently, the nucleus localization is the most frequent protein target in the zinc proteome. Additionally, cytoplasm and mitochondrion localization

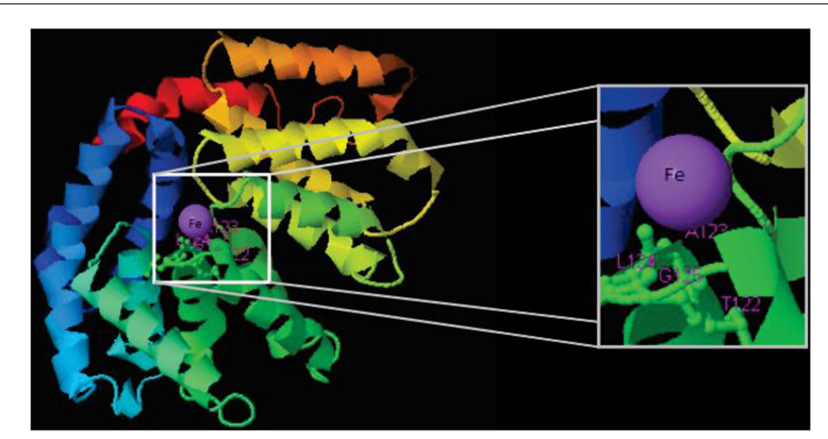

FIGURE 3 | Structural model of a calcium transporter showing that Fe is the putative ligand. Structural model was obtained by using the I-Tasser software.

was also frequent. Corroborating with the high number of metaltransporters, the predicted localization of proteins at the plasma membrane is expressive.

\section{COMPARISON OF PREDICTED METALLOPROTEOMES OF THREE ISOLATES FROM THE PARACOCCIDIOIDES COMPLEX}

The metalloprotein datasets were compared among the three phylogenetic species (PS) by using the BLAST tool. As expected, the comparison showed that most of the proteins are common among the species. Additionally, the specific proteins of each species were identified as well as the specific proteins for two species (Figure 5). Paracoccidioides lutzii presented the highest number of specific metalloproteins, which corroborates with the fact that it belongs to a new species in the genus and it has the greater genome. The metal-binding molecules specific to one or two PSs may be a result of different situations: the encoding gene is specific or the encoding gene is not specific but the metal-binding motif is. In the latter group orthologs with no metal-binding domain or orthologs that bind to a different metal were identified, as revealed by the structural prediction.

A comparison of the copper-proteins revealed that each isolate has one exclusive protein and the other five molecules are specific for two isolates according to the BLAST analysis. The exclusive proteins are not encoded by exclusive genes: the protein from $\mathrm{Pb} 01$ is not exclusive (orthologs with a Cu-binding domain were found) and the proteins from $\mathrm{Pb} 03$ and $\mathrm{Pb} 18$ presented orthologs with no metal binding domain (Supplementary Table 5). Regarding the iron proteome, the results revealed that most of the proteins (102 orthologs) are present in the three phylogenetic species. The $\mathrm{Pb} 18$ and $\mathrm{Pb} 01$ presented six iron-binding molecules that were not found in $\mathrm{Pb} 03$. However, $\mathrm{Pb} 03$ and $\mathrm{Pb} 18$ genomes encode five specific orthologs, whereas $\mathrm{Pb} 01$ and $\mathrm{Pb} 03$ have 3 iron proteins not found in $\mathrm{Pb} 18$. Although the $\mathrm{Pb} 18$ iron proteome has no specific protein, $\mathrm{Pb} 01$ and $\mathrm{P} 03$ present three specific proteins and one specific protein, respectively. None of these proteins are encoded by specific genes. The BLAST search coupled to structural prediction analysis revealed three different situations: a specific iron protein (there are orthologs in other phylogenetic species but a metal-binding protein was not found in one or two species); the iron proteins are not specific (a structural I-Tasser analysis developed iron-dependent models in other 


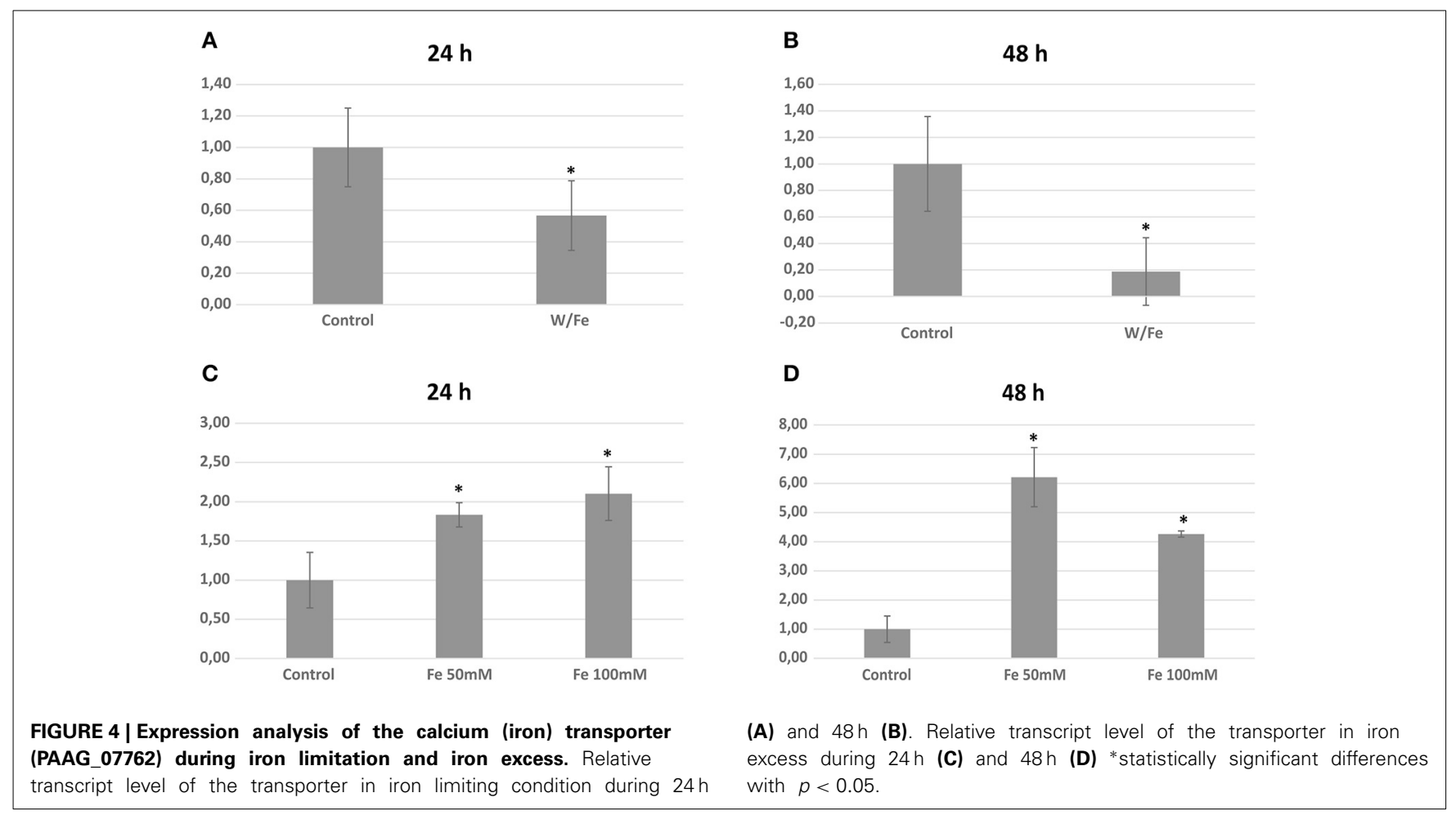

species); or the protein presents many orthologs in the other species that an arbitrary selection could not drive a reliable conclusion. The comparison of the zinc-binding proteomes of three genomes shows that a high portion is conserved among them (Supplementary Table 5). Regarding Pb01 and Pb03, most of the specific $\mathrm{Zn}$ proteins are not encoded by specific genes and, therefore, there are peptides with Zn-binding domains specific to a single phylogenetic species. Proteins encoded by speciesspecific genes were also found, as well as, proteins that are not specific.

\section{METAL DEPENDENT VIRULENCE FACTORS}

Metal essentiality and toxicity is used by a host to defend against invaders, thus metal uptake and homeostasis by pathogens in mammal host tissues are essential for virulence (Hood and Skaar, 2012). Some metalloproteins are essential for the intracellular regulation of metals, as well as for the control of their import and export (Sun et al., 2011). Pathogens must acquire and control metal utilization during infection to survive in their hosts (Silva et al., 2011). Several metalloproteins identified in this work play roles in fungal pathogenesis (Table 3). Classical virulence factors compose the predicted metalloproteomes in Paracoccidioides spp. For example, five superoxide dismutases were found: two are $\mathrm{Cu}$ and $\mathrm{Zn}$-dependent and three are Fe-dependent. Thus, these metals become essential elements to an effective response against ROS production by the host. Laccase enzymes are related to melanin production and iron uptake, which contributes to the virulence of pathogenic fungi present in copper-binding domains. Urease is another enzyme that contributes primarily to fungal pathogenesis and was identified as an iron protein. This protein promotes changes in $\mathrm{pH}$ and toxic effects to increase the fungal

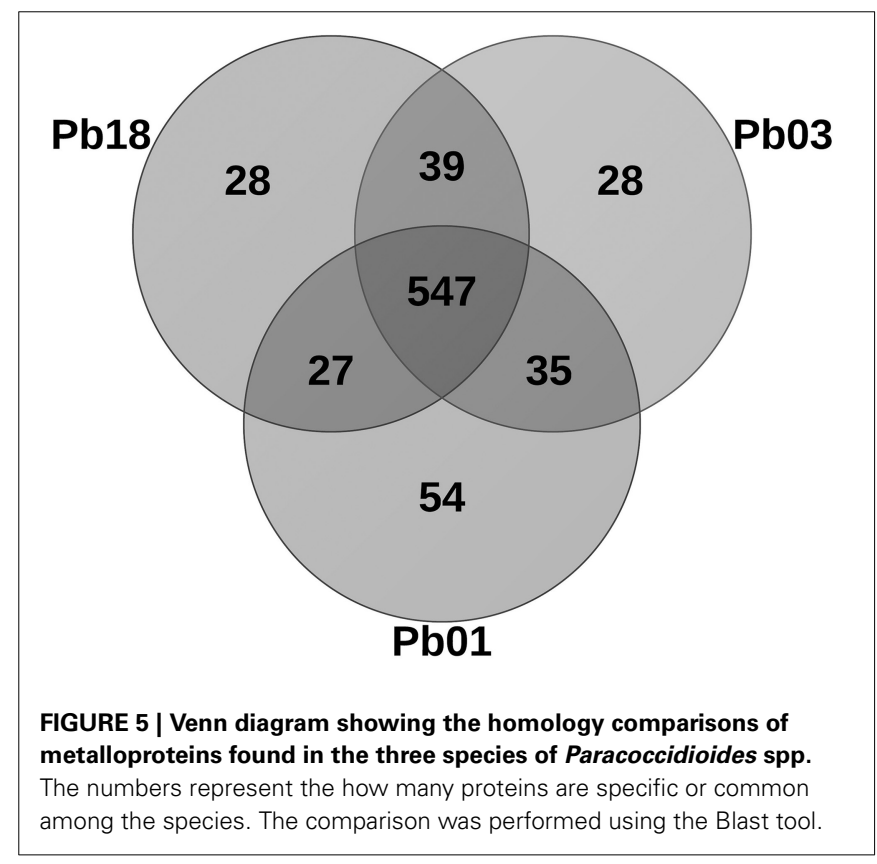

pathogenicity (Mirbod-Donovan et al., 2006). Alcohol dehydrogenases $(\mathrm{ADH})$ are related to the Paracoccidioides spp. response to host mimicking conditions. Five $\mathrm{ADH}$ genes were found to be zinc-binding molecules and one as iron-binding. Additionally, other Zn-binding enzymes related to central carbon metabolism such as fructose 1,6-biphosphate aldolase, triose phosphate isomerase and enolase have moonlight functions related to the adhesion to host cells and tissue dissemination. Protease production 
Table 3 | Metalloproteins described as virulence factors in fungi.

\begin{tabular}{|c|c|c|c|c|c|}
\hline $\begin{array}{l}\text { Pb01 access } \\
\text { number }\end{array}$ & $\begin{array}{l}\text { Pb03 access } \\
\text { number }\end{array}$ & $\begin{array}{l}\text { Pb18 access } \\
\text { number }\end{array}$ & $\begin{array}{l}\text { Protein } \\
\text { description }\end{array}$ & $\begin{array}{l}\text { Virulence factor's } \\
\text { reference }\end{array}$ & $\begin{array}{l}\text { Metal } \\
\text { bound }\end{array}$ \\
\hline PAAG_00610 & PABG_05322 & PADG_06931 & GATA transcription factor & Hwang et al., 2012 & $\mathrm{Zn}$ \\
\hline PAAG_02358 & PABG_04857 & PADG_05497 & GATA factor SREP & Hwang et al., 2012 & $\mathrm{Zn}$ \\
\hline PAAG_04164 & PABG_03954 & PADG_07418 & superoxide dismutase & Cox et al., 2003 & $\mathrm{Zn}$ \\
\hline PAAG_02971 & PABG_00431 & PADG_02842 & $\begin{array}{l}\text { cytosolic } \mathrm{Cu} / \mathrm{Zn} \text { superoxide } \\
\text { dismutase }\end{array}$ & Cox et al., 2003 & $\mathrm{Cu} / \mathrm{Zn}$ \\
\hline PAAG_06363 & PABG_02770 & PADG_01263 & superoxide dismutase & Cox et al., 2003 & $\mathrm{Fe}$ \\
\hline PAAG_02725 & PABG_03204 & PADG_01755 & superoxide dismutase & Cox et al., 2003 & $\mathrm{Fe}$ \\
\hline PAAG_02926 & PABG_03387 & PADG_01954 & superoxide dismutase & Cox et al., 2003 & $\mathrm{Fe}$ \\
\hline PAAG_03681 & PABG_00738 & PADG_03184 & laccase-1 & Zhu et al., 2001 & $\mathrm{Cu}$ \\
\hline PAAG_06004 & PABG_05667 & PADG_05994 & laccase-IV & Zhu et al., 2001 & $\mathrm{Cu}$ \\
\hline PAAG_00163 & PABG_05183 & PADG_07092 & laccase-3 & Zhu et al., 2001 & $\mathrm{Cu}$ \\
\hline PAAG_00954 & PABG_01291 & PADG_03871 & urease & Mirbod-Donovan et al., 2006 & $\mathrm{Fe}$ \\
\hline PAAG_00243 & None & None & alcohol dehydrogenase IV & Pancholi and Chhatwal, 2003 & $\mathrm{Fe}$ \\
\hline PAAG_08903 & PABG_05423 & PADG_05734 & alcohol dehydrogenase & Pancholi and Chhatwal, 2003 & $\mathrm{Zn}$ \\
\hline PAAG_06916 & PABG_02939 & PADG_01454 & alcohol dehydrogenase & Pancholi and Chhatwal, 2003 & $\mathrm{Zn}$ \\
\hline PAAG_06596 & PABG_02619 & None & alcohol dehydrogenase & Pancholi and Chhatwal, 2003 & $\mathrm{Zn}$ \\
\hline PAAG_06715 & PABG_02727 & PADG_01174 & alcohol dehydrogenase & Pancholi and Chhatwal, 2003 & $\mathrm{Zn}$ \\
\hline PAAG_05227 & PABG_07631 & PADG_05031 & alcohol dehydrogenase & Pancholi and Chhatwal, 2003 & $\mathrm{Zn}$ \\
\hline PAAG_04541 & PABG_04316 & PADG_04701 & $\begin{array}{l}\text { alcohol dehydrogenase GroES } \\
\text { domain-containing protein }\end{array}$ & Pancholi and Chhatwal, 2003 & $\mathrm{Zn}$ \\
\hline PAAG_06104 & PABG_06552 & PADG_08012 & fructose-biphosphate aldolase & Pancholi and Chhatwal, 2003 & $\mathrm{Zn}$ \\
\hline PAAG_01995 & PABG_02260 & PADG_00668 & fructose-biphosphate aldolase & Pancholi and Chhatwal, 2003 & $\mathrm{Zn}$ \\
\hline PAAG_02152 & PABG_02388 & PADG_00743 & Class II aldolase family protein & Pancholi and Chhatwal, 2003 & $\mathrm{Zn}$ \\
\hline PAAG_00557 & PABG_03558 & PADG_02132 & mannose-6-phosphate isomerase & Pancholi and Chhatwal, 2003 & $\mathrm{Zn}$ \\
\hline PAAG_00771 & PABG_01457 & PADG_04059 & enolase & Pancholi and Chhatwal, 2003 & $\mathrm{Zn}$ \\
\hline PAAG_07076 & PABG_03073 & PADG_01601 & M6 family metalloprotease & Puccia et al., 1999 & $\mathrm{Zn}$ \\
\hline PAAG_05251 & None & None & High affinity copper transporter & $\begin{array}{l}\text { Bailao et al., 2006; Waterman } \\
\text { et al., } 2012\end{array}$ & $\mathrm{Cu}$ \\
\hline PAAG_07053 & PABG_03057 & PADG_01582 & Copper-transporting ATPase & Walton et al., 2005 & $\mathrm{Cu}$ \\
\hline PAAG_07154 & PABG_02495 & PADG_00917 & Copper-transporting ATPase & Walton et al., 2005 & $\mathrm{Cu}$ \\
\hline PAAG_07762 & PABG_00362 & PADG_02775 & $\begin{array}{l}\text { Calcium transporter (iron } \\
\text { transporter) }\end{array}$ & $\begin{array}{l}\text { Ramanan and Wang, 2000; Jung } \\
\text { et al., 2008; Silva et al., } 2011\end{array}$ & $\mathrm{Fe}$ \\
\hline
\end{tabular}

is a strategy used by several pathogens in host colonization and many proteases are metal-dependent proteins as found in our analysis. Also we found that many peptidases and proteases were related to protein processing rather than virulence. As metals are essential to the molecules of live organisms, the components that control their uptake and utilization have been described as factors that contribute to virulence. Accordingly, several cation/metal transporters were identified in the zinc metalloproteome of the genus Paracoccidioides. Among several zinc-dependent transcription factors the GATA-type Cir1/SREA (PAAG_00610, PABG_05322, PADG_06931/PAAG_02358, and PABG_04857) related to iron homeostasis and virulence in fungi was found. Previous analysis suggested that Paracoccidioides spp. are devoid of a classical high affinity iron transport Ftr (Silva et al., 2011). In the present work, a putatively iron-transporter that contributes to the virulence of $C$. albicans and $C$. neoformans was found (Ramanan and Wang, 2000; Jung et al., 2008). Additionally, copper homeostasis plays an essential role in fungal pathogenesis. High affinity copper transporters (CTR) are key elements in copper uptake in $\mathrm{Cu}$-limiting conditions (Waterman et al., 2007, 2012). The CTR3 of Paracoccidioides spp. was identified in our analysis and its transcripts are induced during infectious mimicking conditions (Bailao et al., 2006; Costa et al., 2007). Other copper transporters (copper-transporting ATPases) are localized at the Golgi complex and a copper-chaperone participates in melanin synthesis in C. neoformans, suggesting their role in virulence (Walton et al., 2005).

\section{DISCUSSION}

The essentiality of metals in biology, such as $\mathrm{Cu}, \mathrm{Fe}$, and $\mathrm{Zn}$, is most related to metal-dependent proteins that play fundamental roles in cells. However, the intracellular levels of these elements have to be tightly controlled because their excess is toxic (Yannone et al., 2012). Regarding pathogenic microorganisms, the uptake, storage, use and distribution of metals are key factors for virulence. To establish infection, fungal pathogens must acquire and use metals in host tissues to cope with the metal scarcity induced by the immune system (Vignesh et al., 2013a,b). 
In this perspective the pathogen also has to adapt to a low level metal environment based on its metalloproteome, changing its metabolism, as much as possible, toward metal independent pathways (Parente et al., 2011).

Not unexpectedly, copper protein functions are most related to ion transport, virulence and general metabolism. The latter include metabolic oxidases such as amine oxidases, glyoxal oxidase, laccases and other oxidases that use the copper redox ability in oxidoreduction/electron-transfer reactions. The dependence of copper by amine oxidases and nitrite reductases suggests that nitrogen metabolism of these fungi is supported by $\mathrm{Cu}$ (Laliberte and Labbe, 2006). The Paracoccidioides spp. Cu proteomes present the primary molecular components of copper uptake and distribution. Among those found, the copper-transporting ATPases are important in metal detoxification and trafficking, as well as, in delivering metal to copper proteins. The laccases are ferroxidases, essential in the reductive iron uptake system and in melanin synthesis, were also found. Other factors important in copper homeostasis are the high affinity $\mathrm{Cu}$-transporting and copper chaperones (Festa and Thiele, 2011, 2012). Additionally, the functional interaction network for $\mathrm{Cu}$-protein suggests a clear linkage among those that orchestrate several $\mathrm{Cu}$-dependent cellular mechanisms, including activities that sustain pathogenesis. It is important to highlight the strong functional association among copper-chaperones, copper-transporting ATPases, and laccases that shows the central roles of those proteins in cellular copper equilibrium. The functional interactions among these proteins are highly confident, suggesting that $\mathrm{Cu}$ acquisition and distribution in the fungal cells are tightly controlled processes preventing increases in free-copper levels.

The analysis of the functional repertoire performed by the putative Fe proteins revealed that the primary roles played by the Fe proteins are the catalysis of redox and electron transfer reactions. At a relatively general level, metabolism is the most representative functional category; it is composed of proteins that belong to amino acid metabolism, biosynthesis of vitamins, nucleotide metabolism, carbohydrate metabolism and others. The amplitude of these metabolic processes is evidence as to how important iron is for basal fungal metabolism. Corroborating that importance, a proteomic analysis in iron starvation condition suggests Paracoccidioides spp. decrease iron dependent enzymes and consequently increase proteins of iron independent pathways (Parente et al., 2011).

Previous work, based on genome-mining, shows that Paracoccidioides spp. genomes encode proteins related to the reductive iron uptake system (Silva et al., 2011). However, no iron transporter was found in this study, and it was assumed that the iron uptake would be performed by a non-specific metal transporter. In the present work, among the iron proteins is a predicted iron-transporter formerly annotated as a calcium transporter. Structural modeling of this transporter suggested that iron is the metal ligand. The quantitative PCR results show that the expression of this transporter is regulated by iron and strongly suggests that it plays a role in metal detoxification rather than in uptake. Moreover, this ambiguity is common in metalloproteome studies because protein metal affinity is a multifactorial event and wrong annotations or structures are frequently detected (Maret,
2010). Future functional studies should be conducted to better elucidate the specific role of this molecule in iron homeostasis. It is well established that defects in iron-sulfur cluster biogenesis or transport induce the expression of iron uptake genes (Chen et al., 2004) and that Fe-S containing proteins participate in sensing iron availability (Muhlenhoff et al., 2010). The presence of many iron-sulfur cluster assembly proteins in the predicted iron proteome described here provides new molecules that may perform roles in Fe homeostasis.

The Zn-proteome of Paracoccidioides spp. represents the majority of the metalloproteins described in the present work. 511 proteins were identified with at least one metal-binding motif, on average. The number of putative zinc proteins found in each species directly correlates with their predicted proteome sizes. As expected, proteins related to gene expression were the most abundant (20\% on average) because transcription factors use zinc for structural reasons to bind to DNA. Thus, this enrichment is responsible for the high frequency of $\mathrm{Zn}$ proteins found in eukaryotes (Andreini et al., 2006b). Among them is the GATA-type transcription factor SREP (accession numbers PAAG_02358, PABG_04857, and PADG_05497), which inhibits the expression of iron-uptake related genes in ironsufficient conditions, and also regulates some iron-independent genes. Additionally, SREP mutants presented abrogated virulence in pathogenic fungi (Gauthier et al., 2010; Hwang et al., 2012). The most populated functional categories include protein folding, processing and degradation. Additionally, some protein importers, kinases/phosphatases and many proteases and peptidases are zinc dependent. Regarding pathogens, the protease activity is intimately connected with virulence (Parente et al., 2005, 2010; Tacco et al., 2009). Thus, zinc homeostasis during infection supports protease based virulence, as well as protein transport and processing in the genus Paracoccidioides.

The Zn proteome of Paracoccidioides spp. presents at least 17 transporters related to $\mathrm{Zn}$ translocation. The Paracoccidioides spp. Zinc proteome contains many metal transporters including Zrt1 and Zrt2, which are localized at the plasma membrane and are related to metal uptake during $\mathrm{Zn}$-limiting and $\mathrm{Zn}$ replete conditions, respectively. The expression of both genes is induced at the fungal cells (Parente et al., 2013). Vacuolar transporters that regulate the cytoplasmic levels of the metal were also identified (Amich et al., 2010). A metallochaperone previously described as a copper-binding protein was identified in this study as a $\mathrm{Zn}$-binding molecule. This is not surprising as the same has been observed in bacterial chaperones (Dainty et al., 2010). Considering Paracoccidioides spp. have no predicted metallothionein (Silva et al., 2011), this molecule could somehow play a role in metal level maintenance.

Recently, a metallomics-based study unveiled that the host immune response against a fungal pathogen promotes zinc limitation in fungal-infected cells. GM-CSF treated macrophages promote zinc uptake to generate ROS as a fungicidal mechanism, and at the same time decrease $\mathrm{Zn}$ availability by metallothionein production and zinc Golgi sequestration (Vignesh et al., 2013a). Thus, metalloproteins that allow Paracoccidioides spp. to uptake and distribute zinc during infection is an essential event for survival in host niches. Paracoccidioides spp. induce 
the production of SODs during oxidative stress, as demonstrated by the proteomic approach (De Arruda Grossklaus et al., 2013). These enzymes are metal dependent and are classified in accordance to their metal as Cu/ZnSOD, MnSOD, FeSOD, and NiSOD (Broering et al., 2013). Paracoccidioides spp. encode for five different SODs: two are copper- and zinc-binding proteins and the other three are Fe-SODs. As these metalloenzymes are important components in the arsenal of fungal virulence factors, an efficient combat against host microbicide ROS rely on a virtuous copper, iron and zinc uptake and homeostasis during infection. Melanization is a virulence factor of many pathogenic fungi (Nosanchuk and Casadevall, 2006; Taborda et al., 2008). Paracoccidioides spp present one tyrosinase and three putative laccases that are key copper-oxidase enzymes in melanin synthesis. Furthermore, metallochaperones and copper transporters play a critical role on melanin production as both proteins participate in Cu-loading in laccases (Festa and Thiele, 2012). The urease production contributes to the virulence of microorganisms (Rutherford, 2014). Although nickel is the most common metal found in urease structures, an iron-binding urease was found in the present analysis. Moreover, as no fungal urease structure is available, these data can be used in future structural studies. Additionally, the enolase, a $\mathrm{Zn}$-binding protein of these pathogens, interacts with host plasminogen favoring the invasion and dissemination steps during host tissue infection (Nogueira et al., 2010).

\section{CONCLUSION}

A previous study described the association of zinc metabolism and fungal virulence based on the identification of zinc-binding proteins and a literature review. The authors used an annotation based approach only, which is not a first line technique for identifying metalloproteins in databases (Andreini et al., 2006b). The present work was used a systematic bioinformatic approach based on domains and conserved structures available in the $\mathrm{PDB}$ to predict the $\mathrm{Cu}, \mathrm{Fe}$, and $\mathrm{Zn}$ proteomes of a pathogenic fungus. The results show that these metals are cofactors of enzymes related to central metabolism and thus are essential for the biology of Paracoccidioides spp. It was also noted that many metalloproteins have no characterized function, indicating that the roles of many metals in biological systems are still unknown. Additionally, some metalloproteins belong to the arsenal of virulence factors taken by Paracoccidioides spp. to be able to infect hosts. Although bioinformatics based studies are important to identify metalloproteins, experimental techniques will be used to characterize the metalloproteins of these pathogenic fungi.

\section{AUTHOR CONTRIBUTIONS}

Gabriel B. Tristão, Mirelle Garcia Silva-Bailão, Clayton Luiz Borges, Gabriele Cavallaro and Leandro do Prado Assunção performed the analysis, data analysis and writing. The following contributed to financial support: Alexandre M. Bailão, Gabriele Cavallaro, Célia M. de Almeida Soares and Clayton Luiz Borges. Leandro do Prado Assunção and Luiz Paulo Araújo dos Santos analyzed the metalloproteome data. Alexandre M. Bailão and
Gabriele Cavallaro conceived the ideas, performed the experimental design and wrote the paper.

\section{SUPPLEMENTARY MATERIAL}

The Supplementary Material for this article can be found online at: http://www.frontiersin.org/journal/10.3389/fmicb.2014. 00761/abstract

\section{REFERENCES}

Amich, J., Vicentefranqueira, R., Leal, F., and Calera, J. A. (2010). Aspergillus fumigatus survival in alkaline and extreme zinc-limiting environments relies on the induction of a zinc homeostasis system encoded by the $\mathrm{zrfC}$ and aspf 2 genes. Eukaryot. Cell 9, 424-437. doi: 10.1128/EC.00348-09

Ammendola, S., Pasquali, P., Pistoia, C., Petrucci, P., Petrarca, P., Rotilio, G., et al. (2007). High-affinity $\mathrm{Zn} 2+$ uptake system $\mathrm{ZnuABC}$ is required for bacterial zinc homeostasis in intracellular environments and contributes to the virulence of Salmonella enterica. Infect. Immun. 75, 5867-5876. doi: 10.1128/IAI.00559-07

Andreini, C., Banci, L., Bertini, I., Elmi, S., and Rosato, A. (2007). Non-heme iron through the three domains of life. Proteins 67, 317-324. doi: 10.1002/prot.21324

Andreini, C., Banci, L., Bertini, I., and Rosato, A. (2006a). Counting the zincproteins encoded in the human genome. J. Proteome Res. 5, 196-201. doi: $10.1021 / \mathrm{pr} 050361 \mathrm{j}$

Andreini, C., Banci, L., Bertini, I., and Rosato, A. (2006b). Zinc through the three domains of life. J. Proteome Res. 5, 3173-3178. doi: 10.1021/pr0603699

Andreini, C., Banci, L., Bertini, I., and Rosato, A. (2008). Occurrence of copper proteins through the three domains of life: a bioinformatic approach. J. Proteome Res. 7, 209-216. doi: 10.1021/pr070480u

Andreini, C., Bertini, I., Cavallaro, G., Decaria, L., and Rosato, A. (2011). A simple protocol for the comparative analysis of the structure and occurrence of biochemical pathways across superkingdoms. J. Chem. Inf. Model. 51, 730-738. doi: 10.1021/ci100392q

Andreini, C., Bertini, I., and Rosato, A. (2004). A hint to search for metalloproteins in gene banks. Bioinformatics 20, 1373-1380. doi: 10.1093/bioinformatics/bth095

Bailao, A. M., Schrank, A., Borges, C. L., Dutra, V., Molinari-Madlum, E. E. W. I., Felipe, M. S. S., et al. (2006). Differential gene expression by Paracoccidioides brasiliensis in host interaction conditions: representational difference analysis identifies candidate genes associated with fungal pathogenesis. Microbes Infect. 8, 2686-2697. doi: 10.1016/j.micinf.2006.07.019

Bertini, I., Gray, R. B., Stiefel, E. I., and Valentini, J. S. (2007). Biological Inorganic Chemistry: Structure and Reactivity. Sausalito, CA: University Science Book.

Bleackley, M. R., and Macgillivray, R. T. (2011). Transition metal homeostasis: from yeast to human disease. Biometals 24, 785-809. doi: 10.1007/s10534-0119451-4

Bocca, A. L., Amaral, A. C., Teixeira, M. M., Sato, P. K., Shikanai-Yasuda, M. A., and Soares Felipe, M. S. (2013). Paracoccidioidomycosis: eco-epidemiology, taxonomy and clinical and therapeutic issues. Fut. Microbiol. 8, 1177-1191. doi: 10.2217/fmb. 13.68

Broering, E. P., Truong, P. T., Gale, E. M., and Harrop, T. C. (2013). Synthetic analogues of nickel superoxide dismutase: a new role for nickel in biology. Biochemistry 52, 4-18. doi: 10.1021/bi3014533

Carrero, L. L., Nino-Vega, G., Teixeira, M. M., Carvalho, M. J., Soares, C. M., Pereira, M., et al. (2008). New Paracoccidioides brasiliensis isolate reveals unexpected genomic variability in this human pathogen. Fungal Genet. Biol. 45, 605-612. doi: 10.1016/j.fgb.2008.02.002

Carter, E. L., Tronrud, D. E., Taber, S. R., Karplus, P. A., and Hausinger, R. P. (2011). Iron-containing urease in a pathogenic bacterium. Proc. Natl. Acad. Sci. U.S.A. 108, 13095-13099. doi: 10.1073/pnas.1106915108

Cassat, J. E., and Skaar, E. P. (2013). Iron in infection and immunity. Cell Host Microbe 13, 509-519. doi: 10.1016/j.chom.2013.04.010

Chen, O. S., Crisp, R. J., Valachovic, M., Bard, M., Winge, D. R., and Kaplan, J. (2004). Transcription of the yeast iron regulon does not respond directly to iron but rather to iron-sulfur cluster biosynthesis. J. Biol. Chem. 279, 29513-29518. doi: 10.1074/jbc.M403209200

Costa, M., Borges, C. L., Bailao, A. M., Meirelles, G. V., Mendonca, Y. A., Dantas, S. F., et al. (2007). Transcriptome profiling of Paracoccidioides brasiliensis yeast-phase cells recovered from infected mice brings new insights into 
fungal response upon host interaction. Microbiology 153, 4194-4207. doi: 10.1099/mic.0.2007/009332-0

Cox, G. M., Harrison, T. S., McDade, H. C., Taborda, C. P., Heinrich, G., Casadevall, A., et al. (2003). Superoxide dismutase influences the virulence of Cryptococcus neoformans by affecting growth within macrophages. Infect. Immun. 71, 173-180. doi: 10.1128/IAI.71.1.173-180.2003

Dainty, S. J., Patterson, C. J., Waldron, K. J., and Robinson, N. J. (2010). Interaction between cyanobacterial copper chaperone Atx1 and zinc homeostasis. J. Biol. Inorg. Chem. 15, 77-85. doi: 10.1007/s00775-009-0555-z

De Arruda Grossklaus, D., Bailao, A. M., Vieira Rezende, T. C., Borges, C. L., De Oliveira, M. A., Parente, J. A., et al. (2013). Response to oxidative stress in Paracoccidioides yeast cells as determined by proteomic analysis. Microbes Infect. 15, 347-364. doi: 10.1016/j.micinf.2012.12.002

Festa, R. A., and Thiele, D. J. (2011). Copper: an essential metal in biology. Curr. Biol. 21, R877-R883. doi: 10.1016/j.cub.2011.09.040

Festa, R. A., and Thiele, D. J. (2012). Copper at the front line of the host-pathogen battle. PLoS Pathog. 8:e1002887. doi: 10.1371/journal.ppat.1002887

Frausto Da Silva, J. J. R., and Williams, R. J. P. (1991). The Biological Chemistry of the Elements. Oxford: Clarendon Press.

Gauthier, G. M., Sullivan, T. D., Gallardo, S. S., Brandhorst, T. T., Vanden Wymelenberg, A. J., Cuomo, C. A., et al. (2010). SREB, a GATA transcription factor that directs disparate fates in Blastomyces dermatitidis including morphogenesis and siderophore biosynthesis. PLoS Pathog. 6:e1000846. doi: 10.1371/journal.ppat.1000846

Hood, M. I., and Skaar, E. P. (2012). Nutritional immunity: transition metals at the pathogen-host interface. Nat. Rev. Microbiol. 10, 525-537. doi: 10.1038/nrmicro2836

Hwang, L. H., Seth, E., Gilmore, S. A., and Sil, A. (2012). SRE1 regulates irondependent and -independent pathways in the fungal pathogen Histoplasma capsulatum. Eukaryot. Cell 11, 16-25. doi: 10.1128/EC.05274-11

Jung, W. H., Sham, A., Lian, T., Singh, A., Kosman, D. J., and Kronstad, J. W. (2008). Iron source preference and regulation of iron uptake in Cryptococcus neoformans. PLoS Pathog. 4:e45. doi: 10.1371/journal.ppat.0040045

Kim, B. E., Nevitt, T., and Thiele, D. J. (2008). Mechanisms for copper acquisition, distribution and regulation. Nat. Chem. Biol. 4, 176-185. doi: 10.1038/nchembio.72

Laliberte, J., and Labbe, S. (2006). Mechanisms of copper loading on the Schizosaccharomyces pombe copper amine oxidase 1 expressed in Saccharomyces cerevisiae. Microbiology 152, 2819-2830. doi: 10.1099/mic.0.28998-0

Maret, W. (2010). Metalloproteomics, metalloproteomes, and the annotation of metalloproteins. Metallomics 2, 117-125. doi: 10.1039/b915804a

Matute, D. R., McEwen, J. G., Puccia, R., Montes, B. A., San-Blas, G., Bagagli, E., et al. (2006a). Cryptic speciation and recombination in the fungus Paracoccidioides brasiliensis as revealed by gene genealogies. Mol. Biol. Evol. 23, 65-73. doi: $10.1093 / \mathrm{molbev} / \mathrm{msj} 008$

Matute, D. R., Sepulveda, V. E., Quesada, L. M., Goldman, G. H., Taylor, J. W., Restrepo, A., et al. (2006b). Microsatellite analysis of three phylogenetic species of Paracoccidioides brasiliensis. J. Clin. Microbiol. 44, 2153-2157. doi: 10.1128/JCM.02540-05

Mirbod-Donovan, F., Schaller, R., Hung, C. Y., Xue, J., Reichard, U., and Cole, G. T. (2006). Urease produced by Coccidioides posadasii contributes to the virulence of this respiratory pathogen. Infect. Immun. 74, 504-515. doi: 10.1128/IAI.74.1.504-515.2006

Muhlenhoff, U., Molik, S., Godoy, J. R., Uzarska, M. A., Richter, N., Seubert, A., et al. (2010). Cytosolic monothiol glutaredoxins function in intracellular iron sensing and trafficking via their bound iron-sulfur cluster. Cell Metab. 12, 373-385. doi: 10.1016/j.cmet.2010.08.001

Murakami, M., and Hirano, T. (2008). Intracellular zinc homeostasis and zinc signaling. Cancer Sci. 99, 1515-1522. doi: 10.1111/j.1349-7006.2008.00854.x

Netz, D. J., Stith, C. M., Stumpfig, M., Kopf, G., Vogel, D., Genau, H. M., et al. (2012). Eukaryotic DNA polymerases require an iron-sulfur cluster for the formation of active complexes. Nat. Chem. Biol. 8, 125-132. doi: 10.1038/nchembio.721

Nevitt, T. (2011). War-Fe-re: iron at the core of fungal virulence and host immunity. Biometals 24, 547-558. doi: 10.1007/s10534-011-9431-8

Nogueira, S. V., Fonseca, F. L., Rodrigues, M. L., Mundodi, V., Abi-Chacra, E. A., Winters, M. S., et al. (2010). Paracoccidioides brasiliensis enolase is a surface protein that binds plasminogen and mediates interaction of yeast forms with host cells. Infect. Immun. 78, 4040-4050. doi: 10.1128/IAI.00221-10
Nosanchuk, J. D., and Casadevall, A. (2006). Impact of melanin on microbial virulence and clinical resistance to antimicrobial compounds. Antimicrob. Agents Chemother. 50, 3519-3528. doi: 10.1128/AAC.00545-06

Pancholi, V., and Chhatwal, G. S. (2003). Housekeeping enzymes as virulence factors for pathogens. Int. J. Med. Microbiol. 293, 391-401. doi: 10.1078/14384221-00283

Parente, A. F., Bailao, A. M., Borges, C. L., Parente, J. A., Magalhaes, A. D., Ricart, C. A., et al. (2011). Proteomic analysis reveals that iron availability alters the metabolic status of the pathogenic fungus Paracoccidioides brasiliensis. PLoS ONE 6:e22810. doi: 10.1371/journal.pone.0022810

Parente, A. F., De Rezende, T. C., De Castro, K. P., Bailao, A. M., Parente, J. A., Borges, C. L., et al. (2013). A proteomic view of the response of Paracoccidioides yeast cells to zinc deprivation. Fungal Biol. 117, 399-410. doi: 10.1016/j.funbio.2013.04.004

Parente, J. A., Costa, M., Pereira, M., and Soares, C. M. (2005). Transcriptome overview of Paracoccidioides brasiliensis proteases. Genet. Mol. Res. 4, 358-371. Available online at: http://www.funpecrp.com.br/gmr/year2005/ vol2-4/Pb10_abstract.htm

Parente, J. A., Salem-Izacc, S. M., Santana, J. M., Pereira, M., Borges, C. L., Bailao, A. M., et al. (2010). A secreted serine protease of Paracoccidioides brasiliensis and its interactions with fungal proteins. BMC Microbiol. 10:292. doi: 10.1186/14712180-10-292

Puccia, R., Juliano, M. A., Juliano, L., Travassos, L. R., and Carmona, A. K. (1999). Detection of the basement membrane-degrading proteolytic activity of Paracoccidioides brasiliensis after SDS-PAGE using agarose overlays containing Abz-MKALTLQ-EDDnp. Braz. J. Med. Biol. Res. 32, 645-649. doi: 10.1590/S0100-879X1999000500019

Ramanan, N., and Wang, Y. (2000). A high-affinity iron permease essential for Candida albicans virulence. Science 288, 1062-1064. doi: 10.1126/science.288.5468.1062

Restrepo, A., and Jimenez, B. E. (1980). Growth of Paracoccidioides brasiliensis yeast phase in a chemically defined culture medium. J. Clin. Microbiol. 12, 279-281.

Rutherford, J. C. (2014). The emerging role of urease as a general microbial virulence factor. PLoS Pathog. 10:e1004062. doi: 10.1371/journal.ppat.1004062

Samanovic, M. I., Ding, C., Thiele, D. J., and Darwin, K. H. (2012). Copper in microbial pathogenesis: meddling with the metal. Cell Host Microbe 11, 106-115. doi: 10.1016/j.chom.2012.01.009

Schneider Rde, O., Fogaca Nde, S., Kmetzsch, L., Schrank, A., Vainstein, M. H., and Staats, C. C. (2012). Zap1 regulates zinc homeostasis and modulates virulence in Cryptococcus gattii. PLoS ONE 7:e43773. doi: 10.1371/journal.pone.0043773

Schrettl, M., and Haas, H. (2011). Iron homeostasis-Achilles' heel of Aspergillus fumigatus? Curr. Opin. Microbiol. 14, 400-405. doi: 10.1016/j.mib.2011.06.002

Shi, W., and Chance, M. R. (2008). Metallomics and metalloproteomics. Cell. Mol. Life Sci. 65, 3040-3048. doi: 10.1007/s00018-008-8189-9

Silva, M. G., Schrank, A., Bailao, E. F. L. C., Bailao, A. M., Borges, C. L., Staats, C. C., et al. (2011). The homeostasis of iron, copper and zinc in Paracoccidioides brasiliensis, Cryptococcus neoformans var. grubi, and Cryptococcus gatii: a comparative analysis. Front. Microbiol. 2:49. doi: 10.3389/fmicb.2011.00049

Silva-Bailao, M. G., Bailao, E. F., Lechner, B. E., Gauthier, G. M., Lindner, H. Bailao, A. M., et al. (2014). Hydroxamate production as a high affinity iron acquisition mechanism in Paracoccidioides spp. PLoS ONE 9:e105805. doi: 10.1371/journal.pone.0105805

Sun, X., Xiao, C. L., Ge, R., Yin, X., Li, H., Li, N., et al. (2011). Putative copperand zinc-binding motifs in Streptococcus pneumoniae identified by immobilized metal affinity chromatography and mass spectrometry. Proteomics 11, 3288-3298. doi: 10.1002/pmic.201000396

Taborda, C. P., Da Silva, M. B., Nosanchuk, J. D., and Travassos, L. R. (2008). Melanin as a virulence factor of Paracoccidioides brasiliensis and other dimorphic pathogenic fungi: a minireview. Mycopathologia 165, 331-339. doi: 10.1007/s11046-007-9061-4

Tacco, B. A., Parente, J. A., Barbosa, M. S., Báo, S. N., Góes, T. D., Pereira, M., et al. (2009). Characterization of a secreted aspartyl protease of the fungal pathogen Paracoccidioides brasiliensis. Med. Mycol. 47, 845-854. doi: $10.3109 / 13693780802695512$

Teixeira, M. D., Theodoro, R. C., Oliveira, F. F., Machado, G. C., Hahn, R. C., Bagagli, E., et al. (2013). Paracoccidioides lutzii sp. nov.: biological and clinical implications. Med. Mycol. 52, 19-28. doi: 10.3109/13693786.2013.794311

Teixeira, M. M., Theodoro, R. C., De Carvalho, M. J., Fernandes, L., Paes, H. C., Hahn, R. C., et al. (2009). Phylogenetic analysis reveals a high level of 
speciation in the Paracoccidioides genus. Mol. Phylogenet. Evol. 52, 273-283. doi: 10.1016/j.ympev.2009.04.005

Valko, M., Morris, H., and Cronin, M. T. (2005). Metals, toxicity and oxidative stress. Curr. Med. Chem. 12, 1161-1208. doi: 10.2174/09298670537 64635

Vignesh, K. S., Landero Figueroa, J. A., Porollo, A., Caruso, J. A., and Deepe, G. S. Jr. (2013a). Granulocyte macrophage-colony stimulating factor induced $\mathrm{Zn}$ sequestration enhances macrophage superoxide and limits intracellular pathogen survival. Immunity 39, 697-710. doi: 10.1016/j.immuni.2013. 09.006

Vignesh, K. S., Landero Figueroa, J. A., Porollo, A., Caruso, J. A., and Deepe, G. S. Jr. (2013b). Zinc Sequestration: arming phagocyte defense against fungal attack. PLoS Pathog. 9:e1003815. doi: 10.1371/journal.ppat.1003815

Von Mering, C., Huynen, M., Jaeggi, D., Schmidt, S., Bork, P., and Snel, B. (2003). STRING: a database of predicted functional associations between proteins. Nucleic Acids Res. 31, 258-261. doi: 10.1093/nar/gkg034

Walter, M. C., Rattei, T., Arnold, R., Guldener, U., Munsterkotter, M., Nenova, K., et al. (2009). PEDANT covers all complete RefSeq genomes. Nucleic Acids Res. 37, D408-D411. doi: 10.1093/nar/gkn749

Walton, F. J., Idnurm, A., and Heitman, J. (2005). Novel gene functions required for melanization of the human pathogen Cryptococcus neoformans. Mol. Microbiol. 57, 1381-1396. doi: 10.1111/j.1365-2958.2005.04779.x

Waterman, S. R., Hacham, M., Hu, G., Zhu, X., Park, Y. D., Shin, S., et al. (2007). Role of a CUF1/CTR4 copper regulatory axis in the virulence of Cryptococcus neoformans. J. Clin. Invest. 117, 794-802. doi: 10.1172/JCI30006

Waterman, S. R., Park, Y. D., Raja, M., Qiu, J., Hammoud, D. A., O'halloran, T. V., et al. (2012). Role of CTR4 in the Virulence of Cryptococcus neoformans. MBio 3:e00285-12. doi: 10.1128/mBio.00285-12
Wilson, D., Citiulo, F., and Hube, B. (2012). Zinc exploitation by pathogenic fungi. PLoS Pathog. 8:e1003034. doi: 10.1371/journal.ppat.1003034

Yannone, S. M., Hartung, S., Menon, A. L., Adams, M. W., and Tainer, J. A. (2012). Metals in biology: defining metalloproteomes. Curr. Opin. Biotechnol. 23, 89-95. doi: 10.1016/j.copbio.2011.11.005

Zhu, X., Gibbons, J., Garcia-Rivera, J., Casadevall, A., and Williamson, P. R. (2001). Laccase of Cryptococcus neoformans is a cell wall-associated virulence factor. Infect. Immun. 69, 5589-5596. doi: 10.1128/IAI.69.9.5589-5596.2001

Conflict of Interest Statement: The authors declare that the research was conducted in the absence of any commercial or financial relationships that could be construed as a potential conflict of interest.

Received: 06 October 2014; accepted: 13 December 2014; published online: 09 January 2015.

Citation: Tristão GB, Assunção LP, dos Santos LPA, Borges CL, Silva-Bailão MG, Soares CMA, Cavallaro G and Bailão AM (2015) Predicting copper-, iron-, and zincbinding proteins in pathogenic species of the Paracoccidioides genus. Front. Microbiol. 5:761. doi: 10.3389/fmicb.2014.00761

This article was submitted to Fungi and Their Interactions, a section of the journal Frontiers in Microbiology.

Copyright () 2015 Tristão, Assunção, dos Santos, Borges, Silva-Bailão, Soares, Cavallaro and Bailão. This is an open-access article distributed under the terms of the Creative Commons Attribution License (CC BY). The use, distribution or reproduction in other forums is permitted, provided the original author(s) or licensor are credited and that the original publication in this journal is cited, in accordance with accepted academic practice. No use, distribution or reproduction is permitted which does not comply with these terms. 